\title{
EVALUASI KUALITATIF PENGGUNAAN ANTIBIOTIK PADA PASIEN ANAK DENGAN METODE GYSSENS DI RSUD KARAWANG ${ }^{1}$ Diany Astuti, ${ }^{2}$ Yuli Nurhayati
}

\author{
${ }^{1}$ Program Studi Farmasi, Fakultas Teknologi dan Ilmu Komputer, Universitas \\ Buana Perjuangan Karawang (dianyastuti@ubpkarawang.ac.id) \\ ${ }^{1}$ Program Studi Farmasi, Fakultas Teknologi dan Ilmu Komputer, Universitas \\ Buana Perjuangan Karawang (fm15.yulinurhayati@ mhs.ubpkarawang.ac.id)
}

\begin{abstract}
ABSTRAK
Peresepan antibiotik untuk pasien anak-anak paling banyak digunakan dalam terapi. Penggunaan Antibiotik untuk anak-anak harus diawasi dan dikendalikan karena penggunaan antibiotik yang tidak terkontrol dan tidak tepat dapat berdampak pada kegagalan efek terapi yang diharapkan dan kemungkinan dapat meyebabkan resistensi antimikroba. Pemakaian antibiotik harus dianalisis untuk mengendalikan resistensi antibiotik. Tujuan penelitian ini untuk menilai rasionalitas terapi antibiotik pada pasien anak. Penelitian ini merupakan analisis deskriptif retrospektif dengan pengambilan data purposive sampling. Subjek dari penelitian adalah rekam medis dari bangsal anak RSUD Karawang. Rasionalitas penggunaan antibiotik adalah penilaian melalui metode gyssens. 147 data dianalisis untuk penelitian ini terdiri dari anak laki-laki $(54,40 \%)$ dan perempuan $(45,60 \%)$ dengan kasus demam tifoid $(53,10)$, diare $(24,5 \%)$ dan bronkopneumonia $(22,4 \%)$. Antibiotik yang digunakan sefotaksim $(71,43 \%)$, amoksisilin $(5,44 \%)$ dan kloramfenikol $(4,76 \%)$. Penilaian antibiotik melalui metode Gyssens adalah skala IVA $(93,20 \%)$, skala IIB $(6,12 \%)$ dan skala IIIA $(0,68 \%)$.
\end{abstract}

Kata Kunci: Antibiotik, Rasionalitas, Metode Gyssens.

\begin{abstract}
Antibiotics prescription for pediatric patients is most widely used in therapy. Antibiotic use for pediatric must be watched and controlled because uncontrolled and inappropriate use of antibiotic can impact on failure of expected therapeutic effect and can also cause the possibility of antimicrobial resistance. Antibiotic consumption is must analyzed for controlling the antibiotics resistance. The aim of study The aim of this study was to assess the rationality of antibiotic therapy in pediatric patients. This research is a retrospective descriptive analysis with purposive data sampling. Subject of study are medical record from pediatric ward in RSUD Karawang. Rationality used of antibiotic is asses through Gyssens method. 147 data was analyzed for this study consist of boys (54,40\%) and girls $(45,60 \%)$ with case of typhoid fever $(53,10)$, diarrhea $(24,5 \%)$ and bronchopneumonia (22,4\%). Antibiotic was use Cefotaxime (71,43\%), Amoxicillin (5,44\%), Chloramphenicol (4,76\%)etc. Assessment antibiotic through Gyssens method are IVA scale (93,20\%), IIB scale (6,12\%) and IIIA scale (0,68\%).

Keyword : Antibiotic, Rationality, Gyssens Method.
\end{abstract}




\section{PENDAHULUAN}

Penyakit infeksi merupakan salah satu masalah kesehatan masyarakat yang paling sering dijumpai yang disebabkan oleh bakteri. Obat yang digunakan untuk mengatasi masalah tersebut adalah antimikroba yang diantaranya antibakteri / antibiotik, antijamur dan antivirus. Pemberian antibiotik merupakan pilihan utama untuk mengatasi infeksi dan golongan obat yang paling banyak digunakan di pelayanan kesehatan serta paling banyak diresepkan termasuk pada pasien anak. Antibiotik untuk pasien anak perlu memperoleh perhatian khusus karena kecenderungan pemakaian yang berlebihan dan tidak tepat akan menyebabkan tidak tercapainya efek terapeutik yang diharapkan.

Menurut penelitian Mora et al (2002) yang dilakukan di Rumah Sakit Anak Nasional Costa Rica menunjukkan 40\% dari 500 pasien anak di rumah sakit mendapatkan terapi antibiotik yang tidak rasional. Satari dkk (2011) di ruang rawat Departemen Ilmu Kesehatan Anak RSUPN Ciptomangunkusumo, melaporkan penggunaan antibiotik pada 49,2\% subjek penelitian. Penelitian AMRIN STUDY tahun 2005, di Surabaya, ditemukan 45\%-76\% penggunaan antibiotik tanpa adanya indikasi, sedangkan di Semarang dilaporkan pemakaian antibiotik tanpa indikasi sebesar 56\%-76\%. Sedangkan pada sebuah kajian rasionalitas penggunaan antibiotik di ICU RSUP Dr Kariadi Semarang periode Juli - Desember 2009 ditemukan ketidaksesuaian penggunaan antibiotik baik secara kuantitas maupun kualitas.

Dampak negatif penggunaan antibiotik yang tidak tepat menyebabkan berkembangnya bakteri resisten antibiotik sehingga meningkatkan kesakitan dan kematian, pengobatan menjadi lebih mahal yang akhirnya menurunkan kualitas pelayanan kesehatan. Resistensi bakteri terhadap antibiotik sangat sulit diatasi dalam pengobatan pasien. Salah satu cara untuk mengatasinya 
dengan menggunakan antibiotik secara rasional, melakukan monitoring dan evaluasi penggunaan antibiotik.

Evaluasi penggunaan antibiotik dapat dilakukan dengan dua metode yaitu secara kuantitatif dan kualitatif. Evaluasi antibiotik secara kualitatif dilakukan dengan menilai ketepatan penggunaan antibiotik dengan menggunakan metode Gyssens. Metode Gyssens merupakan suatu alat untuk mengevaluasi kualitas penggunaan antibiotik yang telah digunakan secara luas di berbagai Negara. Metode ini menilai ketepatan penggunaan antibiotik, seperti ketepatan indikasi, ketepatan pemilihan berdasarkan efektivitas, toksisitas, harga, spektrum, lama pemberian, dosis, interval, rute, dan waktu pemberian (Gyssens, 2005).

\section{METODE PENELITIAN}

Penelitian ini merupakan penelitian deskriptif analitik dengan pengambilan data secara retrospektif yang didasarkan pada catatan rekam medis pasien dengan diagnosa penyakit infeksi. Data yang diambil dari periode Oktober - Desember 2018. Teknik pengambilan sampel menggunakan Purposive sampling yang memenuhi kriteria inklusi. Data kemudian diolah secara statistik dengan menggunakan analisis univariat. Penilaian rasionalitas penggunaan antibiotika dianalisis dengan menggunakan kategori Gyssens berdasarkan Standar Pelayanan Medik Departemen Kesehatan Republik Indonesia.

\section{HASIL DAN PEMBAHASAN}

Sampel penelitian sebanyak 147 pasien. Pengambilan sampel menggunakan teknik Purposive Sampling dimana untuk menilai rasionalitas penggunaan antibiotik menggunakan metode Gyssens. 
Tabel 1. Karakteristik Pasien Terhadap Penggunaan Antibiotik Di RSUD Karawang

\begin{tabular}{lll}
\hline \multicolumn{1}{c}{ Karakteristik } & Frekuensi $(\mathbf{n}=\mathbf{1 4 7})$ & Persentase $\%$ \\
\hline Jenis Kelamin & & \\
Laki - laki & 80 & $54,4 \%$ \\
Perempuan & 67 & $45,6 \%$ \\
Usia & & \\
1 - 5 Tahun & 111 & $75,5 \%$ \\
$6-11$ Tahun & 36 & $24,5 \%$ \\
Diagnosa & & \\
Pneumonia & 33 & $22,4 \%$ \\
Demam Tifoid & 78 & $53,1 \%$ \\
Diare & 36 & $24,5 \%$ \\
\hline
\end{tabular}

Berdasarkan hasil penelitian dapat dilihat pasien yang menggunakan antibiotik anak laki-laki dengan jumlah 80 pasien $(54,4 \%)$ dan anak perempuan sebanyak 67 pasien $(45,6)$ dengan usia 1 - 5 tahun sebanyak 111 pasien $(75,5 \%)$ dan diagnosa yang paling banyak yaitu demam tifoid sebanyak 78 pasien $(53,1)$. Hasil penelitian ini sejalan dengan penelitian Purwaningsih dkk (2015), menyatakan bahwa penggunaan antibiotik pada jenis kelamin laki-laki lebih banyak yaitu 213 pasien (58\%) dan perempuan sebanyak 154 pasien (42\%), dengan usia $1-4$ tahun sebanyak 172 pasien $(46,9)$.

Tabel 4.2 Karakteristik Penggunaan Antibiotik Di ruang Rawamerta RSUD Karawang

\begin{tabular}{|c|c|c|c|}
\hline \multicolumn{2}{|c|}{ Karakteristik } & $\begin{array}{l}\text { Jumlah } \\
(n=147)\end{array}$ & $\begin{array}{c}\text { Persentase } \\
(\%)\end{array}$ \\
\hline \multicolumn{4}{|c|}{ Jumlah Penggunaan Antibiotik } \\
\hline \multicolumn{2}{|c|}{ Antibiotik Tunggal } & 132 & $89,80 \%$ \\
\hline \multicolumn{2}{|l|}{ Kombinasi 2 Antibiotik } & 13 & $8,84 \%$ \\
\hline \multicolumn{2}{|c|}{ Kombinasi > 2 Antibiotik } & 2 & $1,36 \%$ \\
\hline Jenis Antibiotik & Golongan Antibiotik & $\begin{array}{l}\text { Jumlah } \\
(n=147)\end{array}$ & $\begin{array}{c}\text { Persentase } \\
(\%)\end{array}$ \\
\hline Amoksisilin & Penisilin & 8 & $5,44 \%$ \\
\hline Ampisilin & Penisilin & 5 & $3,40 \%$ \\
\hline
\end{tabular}




\begin{tabular}{|c|c|c|c|}
\hline Sefotaksim & Sefalosporin & 105 & $71,43 \%$ \\
\hline Seftriakson & Sefalosporin & 6 & $4,08 \%$ \\
\hline Siprofloksasin & Fluorokuinolon & 1 & $0,68 \%$ \\
\hline Kloramfenikol & Antibiotik Golongan Lain & 7 & $4,76 \%$ \\
\hline Sefotaksim + Ampisilin & Sefalosporin + Penisilin & 1 & $0,68 \%$ \\
\hline Sefotaksim + Gentamisin & $\begin{array}{l}\text { Sefalosporin+ } \\
\text { Aminoglikosida }\end{array}$ & 2 & $1,36 \%$ \\
\hline $\begin{array}{l}\text { Sefotaksim + } \\
\text { Gentamisin+ } \\
\text { Metronidazole }\end{array}$ & $\begin{array}{l}\text { Sefalosporin }+ \\
\text { Aminoglikosida }+ \\
\text { Antibiotik Golongan Lain }\end{array}$ & 2 & $1,36 \%$ \\
\hline $\begin{array}{l}\text { Kloramfenikol + } \\
\text { Ampisilin }\end{array}$ & $\begin{array}{l}\text { Antibiotik Golongan Lain } \\
+ \text { Penisilin }\end{array}$ & 2 & $1,36 \%$ \\
\hline $\begin{array}{l}\text { Kloramfenikol + } \\
\text { Sefotaksim }\end{array}$ & $\begin{array}{l}\text { Antibiotik Golongan Lain } \\
+ \text { Sefalosporin }\end{array}$ & 3 & $2,04 \%$ \\
\hline $\begin{array}{l}\text { Kloramfenikol + } \\
\text { Gentamisin }\end{array}$ & $\begin{array}{l}\text { Antibiotik Golongan Lain } \\
+ \text { Aminoglikosida }\end{array}$ & 1 & $0,68 \%$ \\
\hline $\begin{array}{l}\text { Metronidazol + } \\
\text { Sefotaksim }\end{array}$ & $\begin{array}{l}\text { Antibiotik Golongan Lain } \\
+ \text { Sefalosporin }\end{array}$ & 4 & $2,72 \%$ \\
\hline
\end{tabular}

Berdasarkan tabel diatas Penggunaan antibiotik pada pasien anak yang paling banyak digunakan di ruang Rawamerta RSUD Karawang adalah antibiotik tunggal sebanyak 132 pasien (90\%) dengan golongan sefalosporin yaitu sefotaksim sebanyak 105 pasien (71,4\%). Penelitian ini sejalan dengan Lestari dwi, dkk (2017) di RSUD Prof. Dr. Margono Soekarjo Purwokerto bahwa antibiotik golongan sefalosporin merupakan golongan antibiotik yang paling banyak digunakan dengan hasil $(79,25 \%)$.

Menurut Tjay dan rahardja (2007) Sefalosporin dapat digunakam sebagai terapi demam tifoid tetapi berdasarkan Pedoman Standar Pelayanan Medik (SPM) Penyakit Dalam penggunaan antibiotik pertama pada pasien demam Tifoid adalah kloramfenikol dan alternatif kedua yaitu golongan sefalosporin generasi ketiga. Di Indonesia kloramfenikol masih digunakan sebagai terapi pertama pada pasien demam tifoid karena efektivitasnya terhadap salmonella, harganya lebih murah dan mudah didapatkan. 


\section{Rasionalitas Penggunaan Antibiotik Berdasarkan Metode Gyssens}

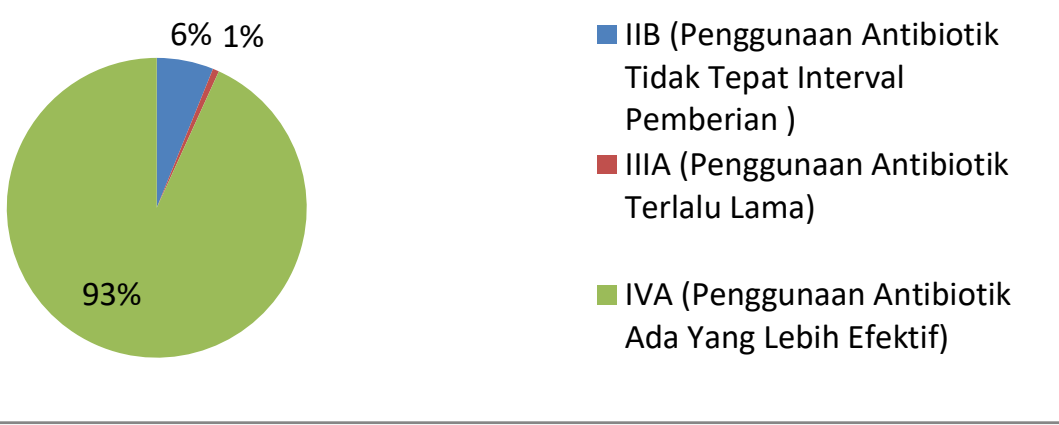

Gambar.1 Rasionalitas Penggunaan Antibiotik Berdasarkan Metode Gyssens Berdasarkan diagram diatas bahwa penilaian antibiotik secara kualitas dilakukan dengan menggunakan alur kategori Gyssens dengan hasil kategori IVA (ada penggunaan antibiotik yang lebih efektif) berjumlah 137 pasien $(93,20 \%)$, kategori IIIA (penggunaan antibiotik terlalu lama) berjumlah 1 pasien $(0,68 \%)$ dan pada kategori IIB (penggunaan antibiotik tidak tepat interval pemberian) terdapat 6 pasien $(6,12 \%)$

Penilaian rasionalitas antibiotik yang dilakukan pada penelitian ini menggunakan Standar Pelayanan Medik Kementrian Kesehatan Republik Indonesia. Standar Pelayanan Medik ini setelah dikaji terdapat perbedaan dalam penentuan pilihan utama antibiotik yang digunakan dalam terapi demam tifoid. Perbedaan ini terjadi baik dengan WHO dan Laporan Indian Pediatric sehingga hasil yang diperoleh berhenti di kategori IVA (Penggunaan Antibiotik Ada Yang Lebih Efektif). Penelitian ini sejalan dengan hasil penelitian Yuniftiadi (2010), RSUP Dr. KARIADI SEMARANG bahwa penilaian rasionalitas penggunaan antibiotik berdasarkan kategori gyssens lebih banyak berhenti pada kategori IVA sebanyak $36,8 \%$, kategori IIIA (penggunaan antibiotik terlalu lama) sebanyak 30,3\% dan kategori IIB (penggunaan antibiotik tidak tepat interval) sebanyak 2,6\%. Penggunaan antibiotik yang kurang tepat tersebut dapat dipengaruhi oleh beberapa faktor diantaranya tidak dilakukannya uji kultur bakteri ataupun uji kepekaan antibiotik dan pencatatan rekam medik yang kurang lengkap. 


\section{KESIMPULAN}

Nilai skala penggunaan antibiotik di ruang Rawamerta RSUD Karawang lebih banyak berhenti pada kategori IVA (ada penggunaan antibiotik yang lebih efektif) sebanyak 137 pasien (93,20\%), kategori IIIA (pengguunaan antibiotik terlalu lama) sebanyak 1 pasien $(0,68 \%)$ dan kategori IIB (penggunaan antibiotik tidak tepat interval pemberian) terdapat 6 pasien $(6,12 \%)$ sehingga penilaian penggunaan antibiotik di ruang Rawamerta RSUD Karawang belum dapat mencapai target rasional kategori 0 menurut skala gyssens.

\section{DAFTAR PUSTAKA}

Febiana, T., Hapsari, M.M., Hapsari, R., 2012, Kajian Rasionalitas Penggunaan Antibiotik Di Bangsal Anak RSUP Dr. Kariadi Semarang Periode Agustus Desember 2011, Jurnal Media Medika Muda, 1-12.

Gyssens IC. Audits for monitoring the quality of antimicrobial prescription. Dalam Van der Meer JW, Gould IM, penyunting. Antibiotic policies theory and practice. New York: Kluwer Academic; 2005.h.197-226.

Kemenkes RI, 2011, Pedoman Pelayanan Kefarmasian Untuk Terapi Antibiotik, Kementerian Kesehatan Republik Indonesia, Jakarta

Lacy, C.F., Armstrong, L.L., Lance, L.L., Goldman, M.P., 2011, Drug Information Handbook with International Trade Names Index, Lexi-Comp.

Mora, Y., Avila-Agüero, M.L., Umaña, M.A., Jiménez, A.L., París, M.M., Faingezicht, I., 2002, Epidemiological Observations of The Judicious Use of Antibiotics in a Pediatric Teaching Hospital, International Journal of Infectious Diseases, 6: 74-77.

Pamela, D.S., 2011, Evaluasi Kualitatif Penggunaan Antibiotika Dengan Metode Gyssens Di Ruang Kelas 3 Infeksi Departemen Ilmu Kesehatan Anak RSCM Secara Prospektif, Tesis, Fakultas MIPA Prodi Studi Ilmu Farmasi, Universitas Indonesia, Jakarta.

Purwaningsih, A. E., rahmawati, F., Wahyono, D., 2015, Evaluasi Penggunaan Antibiotik Pada Pasien Pediatri Rawat Inap. Jurnal Manajemen dan Pelayanan Farmasi. Fakultas Farmasi, Universitas Gadjah Mada, Yogyakarta

Satari HI, Firmansyah A, Theresia. Qualitative evaluation of antibiotic usage in pediatric patients. Pediatr Indones 2011;51:303-309.

Sidabutar S, Satari HI. 2010. Pilihan Terapi Empiris Demam Tifoid pada Anak: Kloramfenikol atau Seftriakson. Jurnal Sari Pediatri. 11. 
The AMRIN study group. Antimicrobial resistance, antibiotic usage and infection control: a self assessment program for Indonesia hospital. Jakarta; Direktorat Jendral Pelayanan Medis Kementrian Kesehatan RI; 2005.h.17-25.

World Health Organization. 2011. Guidelines for the Management of Typhoid Fever. WHO. Zimbabwe

Yuniftiadi, F., Pujo, J.L., Lestari, E.S., 2010, Kajian Rasionalitas Penggunaan Antibiotik di Intensiv Care Unit RSUP Dr. Kariadi Semarang Periode Juli Desember 2009, Karya Tulis Ilmiah, Fakultas Kedokteran Universitas Diponegoro, Semarang. 